\title{
Behavioural Differences in Brown-Norway and Wild-Type Rats Maintained in Standard or Enriched Environment in Response to Novelty in a Familiarised Environment
}

\author{
Wojciech Pisula, Klaudia Modlinska, Anna Chrzanowska, Rafał Stryjek \\ Institute of Psychology, Polish Academy of Sciences, Warsaw, Poland \\ Email: wojciech.pisula@psych.pan.pl
}

Received 27 January 2015; accepted 11 February 2015; published 12 February 2015

Copyright (C) 2015 by authors and Scientific Research Publishing Inc.

This work is licensed under the Creative Commons Attribution International License (CC BY).

http://creativecommons.org/licenses/by/4.0/

(c) (i) Open Access

\begin{abstract}
Maintaining animals in an enriched environment may have different effects on animals depending on their background. Wild-type rats, such as WWCPS (Warsaw Wild Captive Pisula Stryjek) rats, are at an early stage of adaptation to laboratory conditions, and we can hypothesise that enriched laboratory environment provides them with conditions much closer to a natural habitat than standard laboratory cages. The WWCPS rats responded to novelty by orienting their behaviour towards the source of change, followed by rapid habituation of that response. The laboratory rats responded similarly to WWCPS rats immediately after the change, but their increased activity in that section of the experimental cage was not subjected to habituation. We propose, that for animals at early stages of domestication, information-seeking is more important in the regulation of their behaviour than it is for fully domesticated animals. In the latter, it is the stimulus-seeking that dominates behaviour regulation. Laboratory rats, and WWCPS rats showed different profiles of response to maintaining in the enriched laboratory conditions.
\end{abstract}

\section{Keywords}

Domestication, Stimulus Seeking, Information Seeking, Environmental Enrichment, Rat Behavior, Wild-Type Rat, Laboratory Rat, WWCPS

\section{Introduction}

The effects of long-term influence of environmental conditions on behaviour, as well as the anatomical and

How to cite this paper: Pisula, W., Modlinska, K., Chrzanowska, A., \& Stryjek, R. (2015). Behavioural Differences in BrownNorway and Wild-Type Rats Maintained in Standard or Enriched Environment in Response to Novelty in a Familiarised Environment. Psychology, 6, 251-262. http://dx.doi.org/10.4236/psych.2015.63025 
neurochemical structure of the brain have attracted the attention of researchers for decades (Diamond, 2001; Foti, Laricchiuta, Cutuli, De Bartolo, Gelfo, Angelucci, \& Petrosini, 2011; Krech, Rosenzweig, \& Bennett, 1962). One of the ways in which these mechanisms are explored is by studying animals in enriched and impoverished physical and social environments (Fairhurst, Frey, Reichert, Szelest, Kelly, \& Bortolotti, 2011; Lewis, 2004; Mailloux, Edwards, Barry, Rowsell, \& Achorn, 1974; Pisula, Ostaszewski, \& Matysiak, 1992). Environmental enrichment is achieved by providing animals with a cognitively and physically stimulating living space and opportunities for diverse social interaction. Comparisons between groups of animals living in enriched environments and those raised in standard laboratory settings reveal multiple differences. Animals living in enriched conditions perform better in learning tasks (Leggio, Mandolesi, Federico, Spirito, Ricci, Gelfo, \& Petrosini, 2005), exhibit higher exploratory activity, lower fear (Huck \& Price, 1975; Genaro \& Schmidek, 2002), and increased social activity (Morley-Fletcher, Rea, Maccari, \& Laviola, 2003). A number of anatomical and chemical differences in the brain have also been reported (Diamond, 2001; Foti, Laricchiuta, Cutuli, De Bartolo, Gelfo, Angelucci, \& Petrosini, 2011; Krech, Rosenzweig, \& Bennett, 1962). A number of authors researching this area note significant brain plasticity, even in adult animals. Environmental enrichment was found to counteract cognitive impairments caused by, among other things, brain damage and stress (Moncek, Duncko, Johansson, \& Jezova, 2004; Sackett, Novak, \& Kroeker, 1999). Another important issue investigated within the environmental enrichment framework is the animal welfare (Jones, Mason, \& Pillay, 2011; Reinhardt, 2003). Providing animals with environmental stimulation by enriching their physical surroundings has beneficial effects on their functioning in captivity (Swaisgood, White, Zhou, Zhang, \& Lindburg, 2005).

From the beginning of research on the effects of enriched environment on animal behaviour, laboratory mice and rats have played a special part (Boyles, Black, \& Furchtgott, 1965; Manosevitz \& Joel, 1973; McCall, Lester, \& Dolan, 1969). Extensive research on these animals allowed for a comprehensive analysis of the effects of environmental complexity on animal behaviour. Still, we should not ignore the fact that these studies were conducted on laboratory animals. Raised for generations in specific conditions, very different from their natural environment, they have undergone multiple anatomical, physiological and behavioural changes (Barnett, Dickson, \& Hocking, 1979; Blanchard, Flannelly, \& Blanchard, 1986; Huck \& Price, 1975; Lockard \& Haerer, 1968; Price, 1999). This is why the study of how environmental complexity affects the changes of animal behaviour in the process of domestication is particularly important (Lickliter \& Ness, 1990; Mitchell, 1976). For example, R. B. Lockard and H. Haerer (1968) claimed that the living conditions of laboratory animals imitate characteristics of impoverished environment, leading to psychological and physiological degeneration in rats. C. Hughes and R. Boice (1973) and R. Boice (1973, 1977) opposed that view, citing multiple similarities between wild and laboratory rats. More recent reports paint a more complex picture of the effects of domestication on the behaviour of animals (Epp, Barker, \& Galea, 2009; Himmler, Modlinska, Stryjek, Himmler, Pisula, \& Pellis, 2014; Stryjek, Modlińska, \& Pisula, 2012). Multiple studies have shown that strains of laboratory rats may differ in some aspects from one another to a greater extent than they differ from their wild conspecifics (e.g. Fonio, Benjamini, Sakov, \& Golani, 2006; Himmler, Stryjek, Modlinska, Derksen, Pisula, \& Pellis, 2013; Stryjek, Modlińska, \& Pisula, 2012).

In his conclusion from many years of research on domestication, E. O. Price (1999) stated that the associated behavioural modifications are often quantitative. Sensitivity thresholds to social stimuli change, but the form of behaviour remains the same. This view is consistent with earlier findings (e.g. Boice, 1977). Furthermore, it appears that various effects of environmental enrichment observed in wild and laboratory rats may be associated with stages of domestication. From the theoretical standpoint, the same technique of breeding animals in an enriched environment may have different effects on animals depending on their background. Assuming that wild-type rats, such as WWCPS (Warsaw Wild Captive Pisula Stryjek rats-Stryjek \& Pisula, 2008), are at an early stage of adaptation to laboratory conditions, we can hypothesise that enriched laboratory environment provides them with conditions much closer to a natural habitat than standard laboratory cages. As such, this manipulation relieves strong environmental pressure of having to adapt to conditions that are drastically different from those encountered in nature. For laboratory rats, on the other hand, enriched environment is more a way to open new developmental opportunities. Since due to the process of domestication lasting many generations, these animals are adapted to laboratory conditions. This view was empirically confirmed in a seminal study by U. W. Huck \& E. O. Price (1975). They kept wild and laboratory Long-Evans rats in standard (old-type wire cages) and enriched conditions (cages equipped with a variety of objects). Next, the rats were tested in the open field test with the typical measures for this method, including: ambulation, rearing, jumping, facial grooming, 
body grooming, fecal boluses. The authors reported a strong effect of enrichment in wild rats, which were more active in the open field test than their conspecifics raised in standard conditions. The difference between laboratory rats raised in enriched and standard conditions was much smaller. Wild rats raised in standard laboratory cages in the study conducted by Huck \& Price (1975) were subjected to strong environmental pressure by being deprived of spatial stimuli and the ability to manipulate their surroundings. In that sense, enriched environment was closer to natural conditions, and, as a result, less emotogenic than being raised in standard cages. For laboratory rats, environmental enrichment constituted improvement of living conditions, which, however, did not translate into a radical decrease in environmental pressure because of their adaptation to laboratory conditions. In hindsight, and in the light of subsequent findings (Fernández-Teruel, Escorihuela, Castellano, González, \& Tobeña, 1997; Moncek, Duncko, Johansson, \& Jezova, 2004), it seems likely that the interpretation of the results obtained by Huck \& Price (1975) in terms of emotional changes is the most valid one.

The effects of environmental enrichment on emotional processes, including coping with stress, continue to attract the attention of many authors (e.g. Branchi, Santarelli, D’Andrea, \& Alleva, 2013). By contrast, the effects of long-term environmental influence on the behaviour of animals in low stress situations remain relatively unexplored. With the use of testing procedures designed to reduce stress in tested animals, it is possible to assess a wider spectrum of cognitive processes that are not subject to stereotypies due to strong emotional arousal (Pisula, 2003, 2004). For example, research conducted between 2000 and 2012 on laboratory rats shows that in lowstress conditions they usually respond to novelty by approaching its source and exploring a novel or altered object (Pisula, 2003, 2004; Tanaś \& Stryjek, 2008). Nevertheless, so far the results of research on novelty in low stress conditions in the WWCPS rats have been inconclusive. In the study of the WWCPS rats, Tanaś \& Pisula (2011) observed no positive responses, such as approaching the source of novelty. Wistar rats, similarly to other laboratory rats in previous studies (Dellu, Mayo, Vallée, Maccari, Piazza, Le Moal, \& Simon, 1996; FernándezTeruel, Escorihuela, Castellano, González \& Tobeña, 1997), showed strong neophilia. Pisula et al. (2012) reported analogous findings in the study where the WWCPS rats were much more cautious when exploring a lowstress novelty compared to gray short-tailed opossum and laboratory rats. It is unclear whether this difference is associated with the WWCPS rats' emotional or cognitive functioning. The results obtained by Tanaś \& Pisula (2011) indicate the lack of emotional components explaining behavioural differences. However, in study by Pisula et al. (2012), comparative analysis of the WWCPS rats, laboratory rats and gray short-tailed opossum revealed a significant role of emotional arousal as a source of differences between the three strains. One possible way to resolve this issue would be an attempt to stabilise emotional stimulation by introducing low-stress conditions for the experimental protocol.

The subject of the present study was the effect of enriched environment on the behavioural response to novelty tested in a low-stress setup. In the light of numerous publications on the long-term effects of stimulating environment on the emotional and cognitive processes we can assume that wild WWCPS rats subjected to this type of manipulation in low-stress conditions will demonstrate stronger positive responses to novelty than laboratory rats.

\section{Method}

The study employed a 2 (rat strain) $\times 2$ (environment type) $\times 2$ (sex) experimental design

\subsection{Subjects}

The study tested 39 wild rats from F2-F4 generations of the WWCPS strain (19 females and 20 males) and 40 Brown Norway rats (20 females and 20 males). The Brown Norway (BN) rats were bred in the Mossakowski Medical Research Centre of the Polish Academy of Sciences, Warsaw. They arrived to our vivarium at the age of seven weeks. The WWCPS rats were bred and maintained in the facility of the H. Chodkowska School of Management and Law in Warsaw.

Prior to experiments the rats were cared for in accordance with the Regulation of the Polish Minister of Agriculture and Rural Development of 10 March 2006 on laboratory animal care. They were housed in groups of 4 to 5 in Eurostandard type IV cages with ad libitum access to water and standard laboratory fodder. The day/night cycle was $13 \mathrm{~h} / 11 \mathrm{~h}$.

\subsection{Housing Conditions}

One half of the rats were raised in standard conditions (control group), while the other half in enriched environ- 
mental conditions (experimental group). The selection of the groups met the criteria of randomization.

Standard conditions

The rats were raised in groups of 4 - 5 in standard housing cages (Eurostandard Type IV) with ad libitum access to water and standard laboratory feed (Labofeed $\mathrm{H}$ ). The temperature in the vivarium was $21^{\circ} \mathrm{C}-22^{\circ} \mathrm{C}$, humidity 40\% - 60\%, the day/night cycle was $13 \mathrm{~h} / 11 \mathrm{~h}$.

Enriched conditions

In the enriched housing conditions the rats were kept in two $200 \mathrm{~cm} / 100 \mathrm{~cm} / 75 \mathrm{~cm}$ pens (see Figure 1). The floor of each pen was tiled with easy-to-wash tiles. The walls were made of galvanised sheet-plated chipboard. Covers were made of wire mesh mounted on a wooden frame. Each area was equipped with a two-level metal shelf (length $70 \mathrm{~cm}$, width $40 \mathrm{~cm}$, height $40 \mathrm{~cm}$ ). The bottom level of the shelf was made of metal plate, the upper level was made of transparent plastic plate to enable observation of animals on the lower level. One shelf was installed at $14 \mathrm{~cm}$, the other at $40 \mathrm{~cm}$. A wire ladder was fixed to each shelf, enabling the rats to climb to either level. The areas also included two water bottles and a bowl with standard laboratory feed. The floor was covered with wood shavings. Rats were kept in single-sex groups of 10 .

\subsection{Experimental Apparatus}

Exploration was measured in an 835/575/800 mm wooden chamber (Figure 2). The front, raising wall was made of transparent Plexiglas plate. The chamber was divided into three zones of equal areas. The dividing walls between the zones were $435 \mathrm{~mm}$ high. A transporter of $160 \mathrm{~mm}$ in diameter with doors $120 \mathrm{~mm}$ tall and $100 \mathrm{~mm}$ wide was placed in the middle zone. The transporter in which rats were moved from cages to the experimental apparatus served as the starting point for the animals. A mirror suspended from the ceiling enabled experimenters to observe the rats' behaviour in the parts where the view from the front was blocked. The left (B) and right (C) zones contained wooden tunnels $80 \mathrm{~mm}$ high, $120 \mathrm{~mm}$ wide and $200 \mathrm{~mm}$ deep. Tunnels in the zones were open from the front. Animals could enter the tunnels or climb on them.

\subsection{Procedures}

Single-sex groups of 9 - 10 rats from one strain were introduced to housing pens (Figure 1 ) at 40 days of age. Temperature in the vivarium was $21^{\circ} \mathrm{C}-22^{\circ} \mathrm{C}$, humidity $40 \%-60 \%$, the day/night cycle was $13 \mathrm{~h}$ of light and $11 \mathrm{~h}$ of darkness. The open sections of the pens were lit at 75 - $100 \mathrm{~lx}$. Animals had ad libitum access to water and food (Labofeed $\mathrm{H}$ ). The areas were cleaned on a weekly basis.

Until the start of the experiment, the rats in the control group were kept in standard cages in the vivarium and were not subject to any additional manipulation other than routine handling, with modifications described by Stryjek (2008) and Stryjek \& Modlinska (2013).

To record behaviour and responses to novelty, each animal was been placed in the experimental chamber for six minutes once daily, during 15 consecutive days. The experimenter left the room immediately after placing the container with the animal in the middle of zone " $\mathrm{A}$ " of the apparatus and opening the doors of the starting box. Then the animal was free to stay in the starting box or to leave it to explore the chamber. The first ten sessions were the habituation sessions during which the apparatus was arranged in the same way (see Figure 2). Introduction of a novelty (i.e. addition of new tunnel on top of the old ones in the zone "C") took place before the eleventh session. Five more sessions were conducted with the chamber remaining in this new arrangement. Sessions 1st, 2nd, 5th, 6th, 9th through 12th, 14th and 15th were video recorded.

The animals were always introduced into the experimental area in the same sequence. All rats had individual markings on their tails to facilitate identification.

All procedures described in this paper were approved by the 1st Local Ethics Commission in Animal Experimentation, Warsaw, Poland.

\section{Results}

The time spent in each of the three zones of the experimental apparatus (“A”, “B”, or "C”) and the numbers of interactions with objects present in each part were quantified. The data file was built on the basis of videotape records using the EthoLog 2.2 observational software (Ottoni, 2000). In order to reduce irrelevant variance, the data collected in the course of the experiment were aggregated into four categories that from this point will be called "phases”. Phase I consisted of data collected during Sessions 1, 2 and 5, Phase II consisted of data col- 


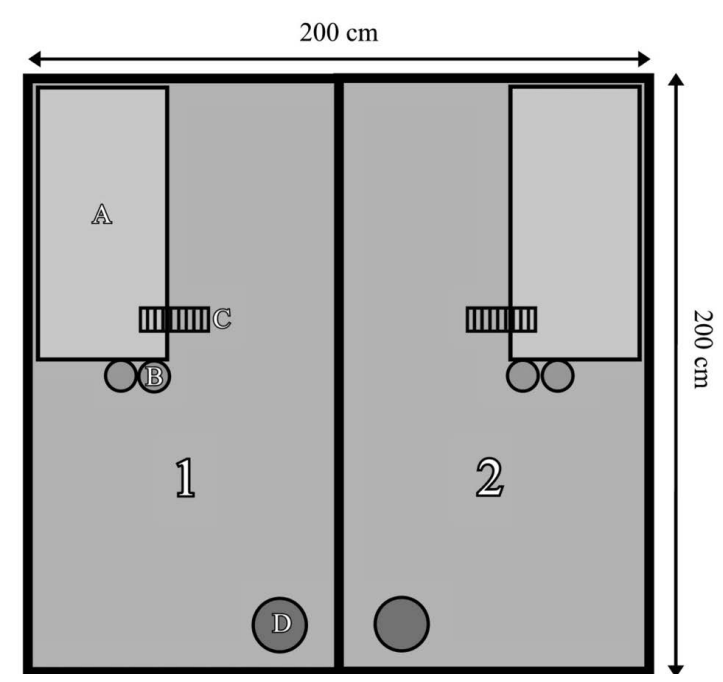

Figure 1. Housing pens (1) male section, (2) female section, (A) two-level shelf, (B) water bottles, (C) ladder, (D) feed bowl.
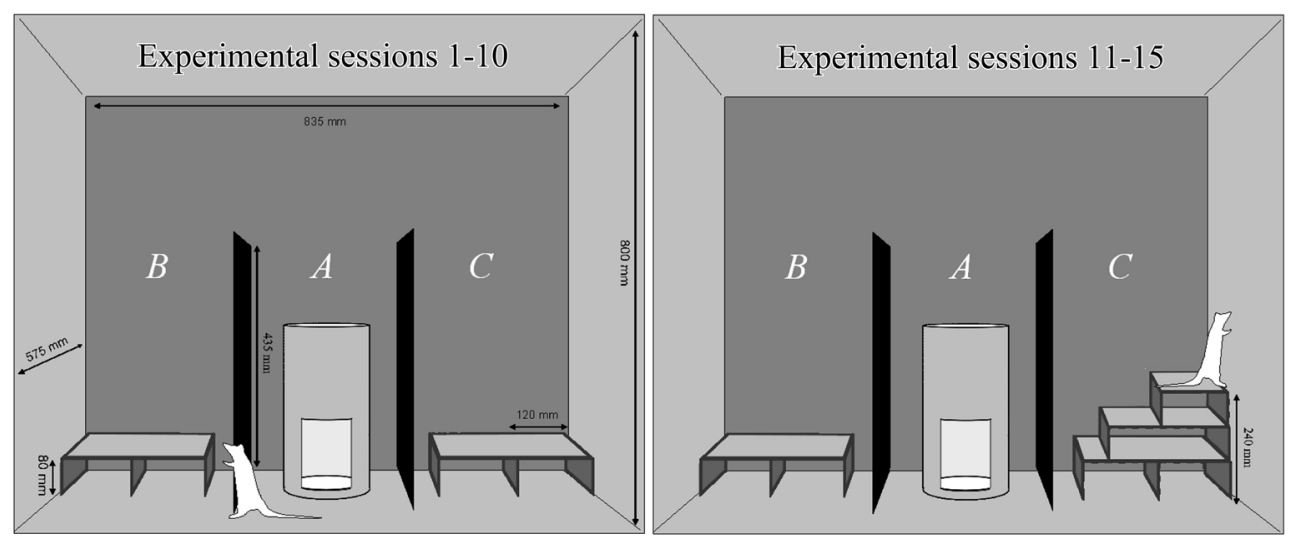

Figure 2. Experimental apparatus used in this study. Above: Experimental area arrangement in habituation sessions 1 - 10 (before manipulation). Below: Experimental area arrangement in sessions 11 - 15 (after manipulation). (A) Starting zone; (B) Zone with permanent configuration of tunnels; (C) Zone with novelty in tunnel's arrangement.

lected during Sessions 6, 9 and 10, Phase III of data collected during Sessions 11 and 12, and Phase IV of data collected during Sessions 14 and 15.

As a measure of stress response, the amount of time each rat spent on grooming was assessed (Komorowska \& Pisula, 2003; Thor et al., 1988).

The experimental design applied in this study was based on a repeated measure, and therefore our main focus is on the interactions among line, sex, and trial effects. Moreover, since the main goal of this study is to test the response of two selected lines of rats to the environmental change, we decided to analyse the environmental effects, sex effects and repeated measure effects within the two lines independently. The main comparisons therefore will be based on the within line effects of sex, environment and repeated measures (which also involves introduction of novelty during the testing phases). The main statistical procedure applied is ANOVA with sex and environment as between subject factors and measurement (involving introduction of novelty) as within subject factor.

\subsection{Grooming}

WWCPS rats demonstrated a distinctive pattern of change in grooming in response to the introduction of novelty in the experimental chamber. The change involved a marked decrease in grooming beginning from Phase 3 (no- 
velty effect) (see Figure 3). The size of the effect varied depending on sex and type of housing, which translated into interaction effects. The interaction effects sex x measurement $[F(3,108)=21.396, p<0.001]$ and environment $\mathrm{x}$ measurement $[\mathrm{F}(3,108)=18.988, p<0.001]$ were found.

The Brown Norway rats exhibited significantly less grooming than WWCPS rats throughout the study. In BN rats, there was a weak factor effect of measurement $[\mathrm{F}(3,108)=2.707, p<0.05]$ demonstrated by increased grooming in the initial experimental sessions and in those after the introduction of novelty (see Figure 3 ).

\subsection{Interactions with the Transporter}

WWCPS rats showed a steady drop in the interactions with the transporter (a direct physical contact with any part of the transporter) in Phases I-III. Due to the differences in effect size, an analysis showed a major effect of measurement $[\mathrm{F}(3,108)=7.373, p<0.001]$ as well as interaction effects of sex x measurement $[\mathrm{F}(3,108)=$ $27.518, p<0.001]$ and environment $x$ measurement $[F(3,108)=25.915, p<0.001]$.

A different pattern emerged in BN rats: the females exhibited a marked decrease in interactions with the transporter between the second and third phases. Statistical analysis yielded interaction effect for sex $\mathrm{x}$ measurement $[\mathrm{F}(3,108)=11.027, p<0.001]$ (see Figure 4).

\subsection{Interactions with Objects in Zone "B"}

The WWCPS rats interacted more with tunnels in Zone "B" of the experimental cage during the habituation part of the experiment (Phases I and II). The number of interactions decreased significantly following the introduction of novelty in Zone "C" (cf. Figure 6). Differences in the size of that effect resulted in interaction effects of sex $x$ measurement $[F(3,108)=19.161, p<0.001]$ and environment $x$ measurement $[F(3,108)=18.807, p<$ $0.001]$.

The pattern was different in the BN rats: the number of interactions with tunnels in zone " $\mathrm{B}$ " of the experimental cage decreased in Phase IV (Figure 5). Due to differences in the steepness of that decrease, statistical analysis yielded interaction effect sex x environment x measurement $[\mathrm{F}(3,108)=3.090, p<0.05]$.

\subsection{Interactions with Objects in Zone "C"}

The WWCPS rats demonstrated a significant increase in the number of interactions with objects/tunnels in zone "C" of the experimental cage in Phase III, followed by a steep decline in Phase IV $[\mathrm{F}(3,108)=7.788, p<$ $0.001]$. In addition, ANOVA yielded interaction effects sex $\mathrm{x}$ measurement $[\mathrm{F}(3,108)=15.160, p<0.001]$ and environment $\mathrm{x}$ measurement $[\mathrm{F}(3,108)=15.054, p<0.001]$, which, however, have no bearing on the nature of the relationship (see Figure 6).
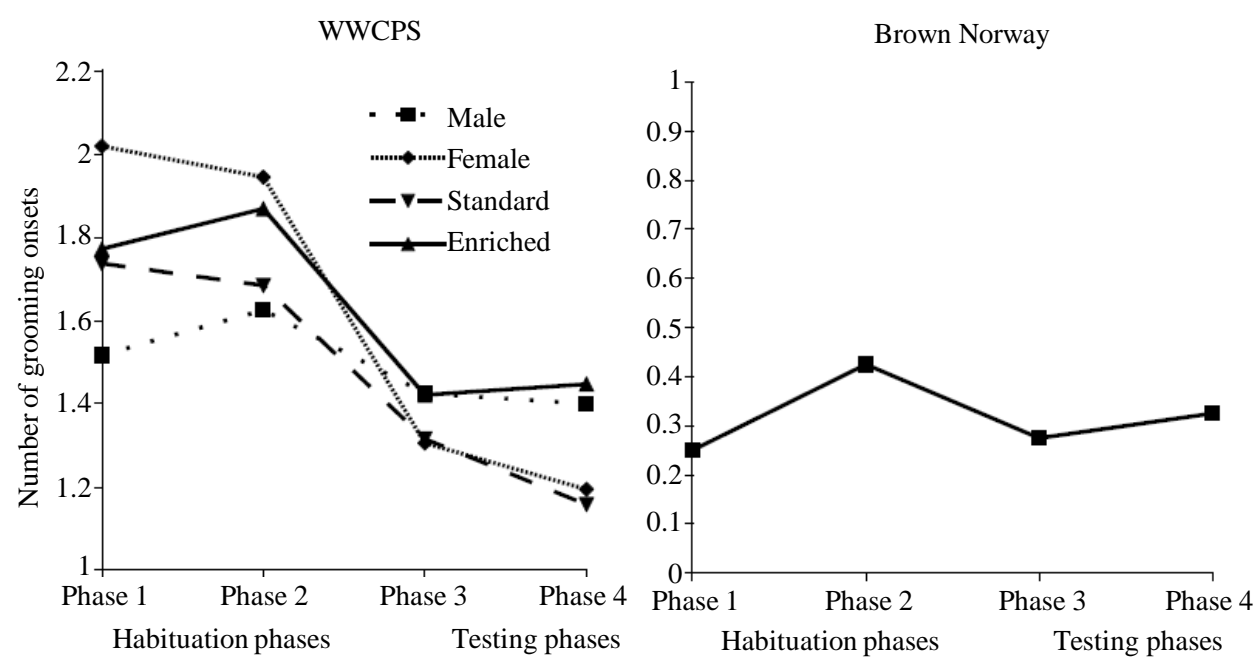

Figure 3. Number of grooming onsets in respective groups of animals. Means of the effects of sex and environment across trial (phases of measurement) for WWCPS rats and of the trial factor for $\mathrm{BN}$ rats are shown. 
WWCPS

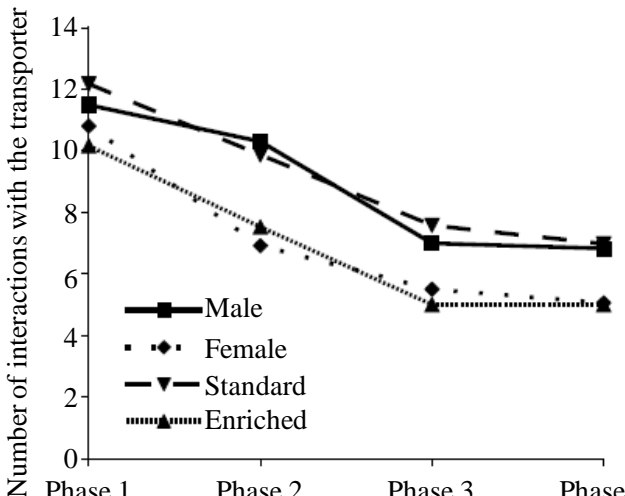

Habituation phases

Testing phases

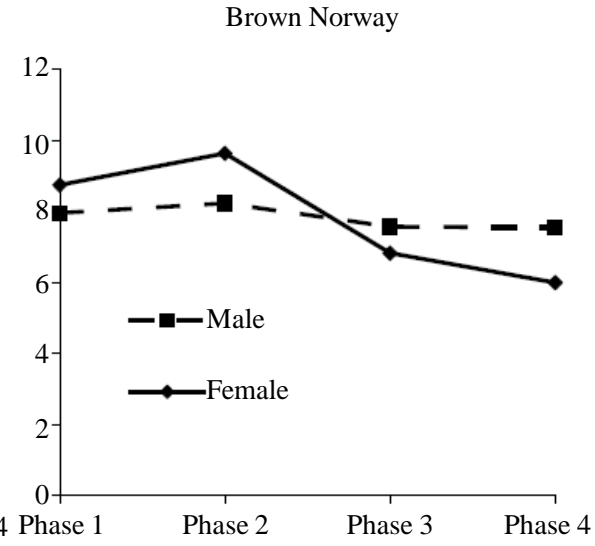

Habituation phases

Testing phases

Figure 4. Number of interactions with the transporter in respective groups of animals. Means of the effects of sex and environment across trial for WWCPS rats and of the sex $\mathrm{x}$ trial factor for $\mathrm{BN}$ rats are shown.
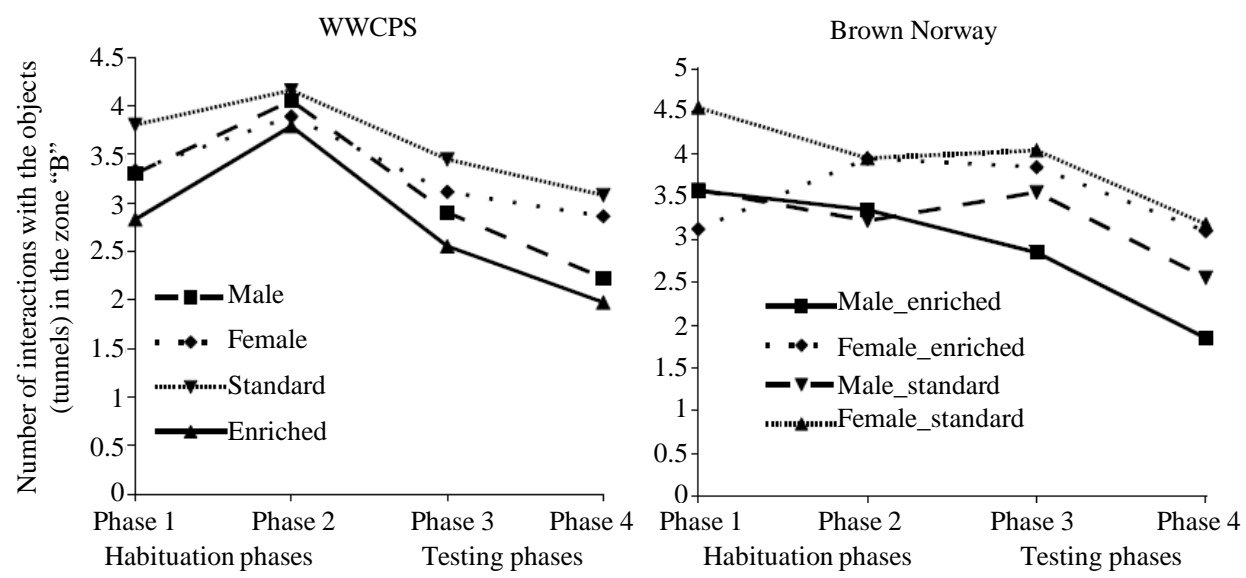

Figure 5. Number of interactions with tunnels in the zone "B" in respective groups of animals. Means of the effects of sex and environment across trial for WWCPS rats and of the sex x environment $\mathrm{x}$ trial factor for $\mathrm{BN}$ rats are shown.
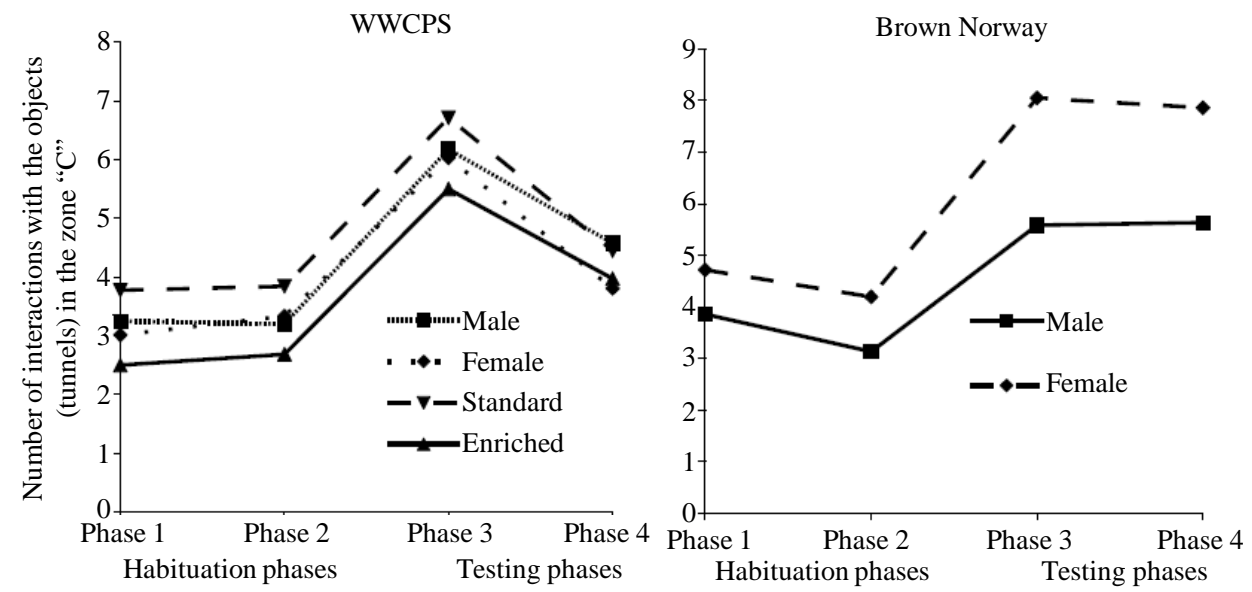

Figure 6. Number of interactions with tunnels in the zone " $\mathrm{C}$ " in respective groups of animals. Means of the effects of sex and environment across trial for WWCPS rats and of the sex x environment $\mathrm{x}$ trial factor for $\mathrm{BN}$ rats are shown. 
The BN rats showed a comparable pattern of responses to novelty in Zone "C” of the experimental cage. Similarly to the WWCPS rats, it involved an increase in object interaction in Phase III. However, unlike in the WWCPS rats, in the BN rats there was no decline in that activity in Phase IV. An ANOVA yielded the main effect of measurement $[\mathrm{F}(3,159)=64.835, p<0.001]$ and an interaction effect of sex x measurement $[\mathrm{F}(3,159)$ $=5.542, p<0.01]$ in the form of stronger response to the novelty among $\mathrm{BN}$ females.

\subsection{Rearing}

The WWCPS rats presented a complex picture of changes in rearing in response to novelty. The effects of sex $x$ measurement $[\mathrm{F}(3,159)=26.346, p<0.001]$ and environment $\mathrm{x}$ measurement $[\mathrm{F}(3,159)=27.041, p<0.001]$ interactions involved the fact that males and rats raised in standard conditions showed much higher initial levels of rearing than their counterparts, followed by a marked decrease when novelty was introduced in the experimental cage. Females and rats raised in enriched conditions presented lower initial rearing and less steep decline in that activity. Two patterns emerged in the BN rats. During the experiment, there was a steady decrease in rearing $[\mathrm{F}(3,108)=13.882, p<0.001]$. In addition, there was the effect of environment $\mathrm{x}$ measurement interaction $[\mathrm{F}(3,108)=2.837, p<0.05]$ in that the enriched environment rats achieved their trough results in Phase III, while their counterparts raised in standard conditions in Phase IV (Figure 7).

\section{Discussion}

The analysis of grooming revealed differences in profiles for that activity between Brown Norway laboratory rats and wild-type WWCPS rats. Firstly, the initial level of that behaviour is several times higher in the latter than in the former (Figure 3). The difference is so large that it hardly requires statistics to prove it. This finding is consistent with the seminal result obtained by Hughes (1975) and the results of our previous studies (Tanaś \& Pisula, 2011). All WWCPS rats responded to modification in the experimental cage with a significant decline in grooming. It can be hypothesised that the cognitive task of having to integrate new elements with existing information resources had an inhibiting effect on grooming, which is typically interpreted as a symptom of emotionality and indicator of the level of stress (Komorowska \& Pisula, 2003). Cognitive effort is often thought to inhibit emotion (Christoff, Ream, \& Gabrieli, 2004). Presumably the novelty introduced in the experimental cage affected that aspect of behavioural organisation more in WWCPS rats than in their laboratory conspecifics. However, in the former, the effect of rearing conditions on grooming was also present.

The analysis of the animals' interactions with the transporter, used to carry them to the experimental chamber, revealed a different response pattern for either strain. Sex differences were present in Brown Norway rats. Males exhibited the same level of transporter interaction for the duration of the experiment. Females, on the other hand, showed a marked decrease in Phase III, i.e. after the introduction of novelty in the experimental cage. All WWCPS rats demonstrated a similar pattern of changes, with transporter interactions decreasing progressively

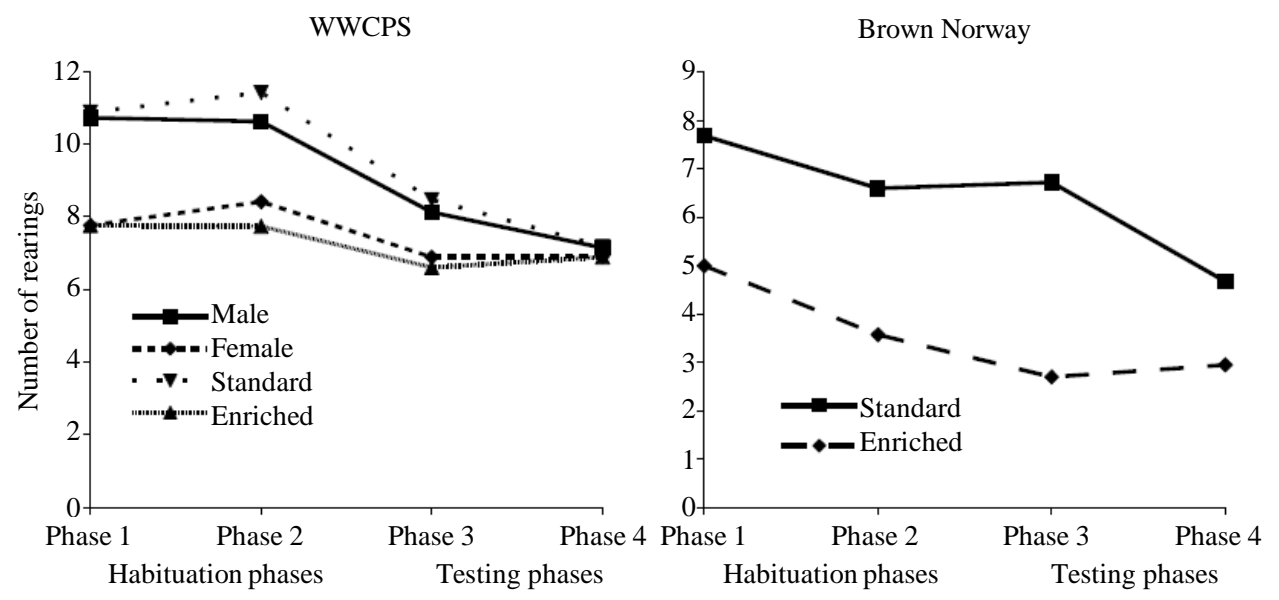

Figure 7. Number of rearings in respective groups of animals. Means of the effects of sex and environment across trial for WWCPS rats and of the environment $\mathrm{x}$ trial factor for $\mathrm{BN}$ rats are shown. 
in all phases of the experiment. Since the transporter was a fixed element of the environment, it can be assumed that changes in interaction level were less a function of the rats' cognitive processes than emotional phenomena. Presumably, rats are relatively attracted to the darkened interior of the transporter. Again, housing conditions proved to have a significant effect on the behaviour of wild rats.

The two strains behaved differently in the section of the experimental cage marked as Zone "B", where no alterations were made to the setting. The WWCPS rats raised in enriched environmental conditions exhibited a decrease in the number of interactions with objects in that zone immediately following the introduction of novelty in Zone "C" and in the last phase of the experiment. By contrast, Brown Norway rats raised in standard conditions showed no changes in the number of interactions with objects in that part of the cage when novelty was introduced in Zone " $C$ ". In Brown Norway rats interactions declined only in the final phase of the experiment. This is a departure from the data obtained in an earlier study (Pisula, Turlejski, Stryjek, Nałęcz-Tolak, Grabiec, \& Djavadian, 2012), in which laboratory rats (Wistar) showed increased interaction in the unaltered part of the experimental cage, and no such changes were observed in WWCPS rats.

The key aspect in the analysis of the effects obtained is the response of the rats in the study to the introduction of novelty in Zone “C”. In Zone “C”, a new object was introduced to augment the novelty, and the number of tunnels was increased to boost complexity. The WWCPS rats exhibited a pattern of behaviour that can be described in terms of a response to novelty that involved orienting their behaviour towards the source of change (zone with a tunnel added), followed by rapid habituation of that response. The laboratory rats (Brown Norway) responded similarly to WWCPS rats immediately after the change, but their increased activity in that section of the experimental cage was not subject to habituation, i.e. the level of activity remained constant over subsequent sessions. From that we may infer that wild rats, similarly to their laboratory counterparts, relocated their exploratory behaviour to the area where novelty appears, and then that activity is relatively quickly extinguished. This could mean that undomesticated rats (WWCPS) exhibit greater behavioural plasticity with respect to changes in their environment.

As was the case with other variables, the WWCPS rats exhibited observable effects of housing conditions on the level of exploration in the altered and unaltered sectors. As far as rearing is concerned, the behavioural patterns in both strains were similar. Rats raised in standard conditions performed more rearing behaviour than those housed in enriched environment pens. There were sex differences in the WWCPS rats: females were rearing more than males. Both the environmental and sex effects disappeared when novelty was introduced in the cage housing the WWCPS rats. By contrast, in Brown Norway rats the effect of the environment was not extinguished in later sessions.

Jones, Mason, \& Pillay (2011) and Latham \& Mason (2010) demonstrated the role of the factor called environmental downshift. This procedure involves moving animals housed in enriched environmental conditions to standard laboratory cages for a period immediately preceding measurements. This is a key element of the protocol, which had to be taken into account in the present study. The procedure was required due to the treatment of WWCPS rats (Stryjek, 2008; Stryjek \& Modlińska, 2013). Seven days before tests, rats kept in enriched conditions were moved to standard cages to ensure standardisation of the appropriate measurement procedure. The research by Jones, Mason, \& Pillay (2011) and Latham \& Mason (2010) quoted above were rooted in the theoretical framework of animal welfare. Nevertheless, the effects identified in those experiments are relevant for basic research.

It appears that, as postulated by classic theories of behavioural motivation, rats' activity is regulated primarily by two major components: stimulation-seeking and information-seeking (Hebb, 1955; Pisula, 2007). It appears that the specific of behaviour and its changes due to environmental factors in WWCPS and Brown Norway rats can be explained by the dominant role of a different regulating component. A general idea that can be extrapolated from the results of the present study is that for animals at early stages of domestication (wild animals raised in a laboratory for 2 - 3 generations, i.e. WWCPS rats), information-seeking is more important in the regulation of their behaviour than it is for fully domesticated animals. In the latter, on the other hand, it is the stimulus-seeking that dominates. The following arguments support this claim:

- rapid habituation to environmental changes in WWCPS rats' behavioural profile

- delayed changes (Zones B, A, grooming, rearings) in the behaviour of Brown Norway rats in response to environmental change

- persistent activity around altered objects in Zone C in Brown Norway rats, which can be interpreted as a sign of stimulus seeking (more complex environment offers more stimuli). 
Moreover, a characteristic variable discriminating wild and laboratory rats proved to be the duration of grooming. WWCPS rats demonstrated more profound behavioural symptoms of stress. It also appears that wild rats are more sensitive to the conditions in which they are raised. The effect of housing environment was present in all variables of interest. The results seem to hold some importance for the understanding of the phenomenon of domestication process.

\section{Conclusion}

Animals that are different in terms of the domestication process advancement, respond to environmental enrichment in different ways. Individuals that are fully domesticated, are mostly driven by the changes in stimulating properties of the environment. On the other hand, individuals that are less advanced in the process of domestication, respond mainly to the information involved in the change of stimulus field. Therefore, animals of the same species, but belonging to subpopulations being at various levels of domestication, seem to be a valuable comparative model, to study behavioral development in the context of domestication processes.

\section{Acknowledgements}

This study was funded by the research project of The National Science Centre \#UMO-2013/09/B/HS6/03435.

\section{References}

Barnett, S. A., Dickson, R. G., \& Hocking, W. E. (1979). Genotype and Environment in the Social Interactions of Wild and Domestic "Norway" Rats. Aggressive Behavior, 5, 105-119. http://dx.doi.org/10.1002/1098-2337(1979)5:2<105::AID-AB2480050202>3.0.CO;2-U

Blanchard, R. J., Flannelly, K. J., \& Blanchard, D. C. (1986). Defensive Behavior of Laboratory and Wild Rattus Norvegicus. Journal of Comparative Psychology, 100, 101-107. http://dx.doi.org/10.1037/0735-7036.100.2.101

Boice, R. (1973). Domestication. Psychological Bulletin, 80, 215-230. http://dx.doi.org/10.1037/h0034893

Boice, R. (1977). Burrows of Wild and Albino Rats: Effects of Domestication, Outdoor Raising, Age, Experience, and Maternal State. Journal of Comparative and Physiological Psychology, 91, 649-661. http://dx.doi.org/10.1037/h0077338

Boyles, W. R., Black, R. W., \& Furchtgott, E. (1965). Early Experience and Cardiac Responsivity in the Female Albino Rat. Journal of Comparative and Physiological Psychology, 59, 447-449. http://dx.doi.org/10.1037/h0022043

Branchi, I., Santarelli, S., D’Andrea, I., \& Alleva, E. (2013). Not All Stressors Are Equal: Early Social Enrichment Favors Resilience to Social but Not Physical Stress in Male Mice. Hormones and Behavior, 63, 503-509. http://dx.doi.org/10.1016/j.yhbeh.2013.01.003

Christoff, K., Ream, J. M., \& Gabrieli, J. D. E. (2004). Neural Basis of Spontaneous thought Processes. Cortex, 40, 623-630. http://dx.doi.org/10.1016/S0010-9452(08)70158-8

Dellu, F., Mayo, W., Vallée, M., Maccari, S., Piazza, P. V., Le Moal, M., \& Simon, H. (1996). Behavioral Reactivity to Novelty during Youth as a Predictive Factor of Stress-Induced Corticosterone Secretion in the Elderly-A Life-Span Study in Rats. Psychoneuroendocrinology, 21, 441-453. http://dx.doi.org/10.1016/0306-4530(96)00017-0

Diamond, M. C. (2001). Response of the Brain to Enrichment. Anais Da Academia Brasileira de Ciências, 73, 211-220. http://dx.doi.org/10.1590/S0001-37652001000200006

Epp, J. R., Barker, J. M., \& Galea, L. A. M. (2009). Running Wild: Neurogenesis in the Hippocampus across the Lifespan in Wild and Laboratory-Bred Norway Rats. Hippocampus, 19, 1040-1049. http://dx.doi.org/10.1002/hipo.20546

Fairhurst, G. D., Frey, M. D., Reichert, J. F., Szelest, I., Kelly, D. M., \& Bortolotti, G. R. (2011). Does Environmental Enrichment Reduce Stress? An Integrated Measure of Corticosterone from Feathers Provides a Novel Perspective. PLOS ONE, 6, e17663. http://dx.doi.org/10.1371/journal.pone.0017663

Fernández-Teruel, A., Escorihuela, R. M., Castellano, B., González, B., \& Tobeña, A. (1997). Neonatal Handling and Environmental Enrichment Effects on Emotionality, Novelty/Reward Seeking, and Age-Related Cognitive and Hippocampal Impairments: Focus on the Roman Rat Lines. Behavior Genetics, 27, 513-526.

http://dx.doi.org/10.1023/A:1021400830503

Fonio, E., Benjamini, Y., Sakov, A., \& Golani, I. (2006). Wild Mouse Open Field Behavior Is Embedded within the Multidimensional Data Space Spanned by Laboratory Inbred Strains. Genes, Brain, and Behavior, 5, 380-388. http://dx.doi.org/10.1111/j.1601-183X.2005.00170.x

Foti, F., Laricchiuta, D., Cutuli, D., De Bartolo, P., Gelfo, F., Angelucci, F., \& Petrosini, L. (2011). Exposure to an Enriched Environment Accelerates Recovery from Cerebellar Lesion. The Cerebellum, 10, 104-119. 
http://dx.doi.org/10.1007/s12311-010-0236-z

Genaro, G., \& Schmidek, W. R. (2002). The Influence of Handling and Isolation Postweaning on Open Field, Exploratory and Maternal Behavior of Female Rats. Physiology \& Behavior, 75, 681-688. http://dx.doi.org/10.1016/S0031-9384(02)00661-3

Hebb, D. O. (1955). Drives and the CNS (Conceptual Nervous System). Psychological Review, 62, 243-254. http://dx.doi.org/10.1037/h0041823

Himmler, B. T., Stryjek, R., Modlinska, K., Derksen, S. M., Pisula, W., \& Pellis, S. M. (2013). How Domestication Modulates Play Behavior: A Comparative Analysis between Wild Rats and a Laboratory Strain of Rattus norvegicus. Journal of Comparative Psychology, 127, 453-464. http://dx.doi.org/10.1037/a0032187

Himmler, S. M., Modlinska, K., Stryjek, R., Himmler, B. T., Pisula, W., \& Pellis, S. M. (2014). Domestication and Diversification: A Comparative Analysis of the Play Fighting of the Brown Norway, Sprague-Dawley, and Wistar Laboratory Strains of (Rattus norvegicus). Journal of Comparative Psychology, 128, 318-327. http://dx.doi.org/10.1037/a0036104

Huck, U. W., \& Price, E. O. (1975). Differential Effects of Environmental Enrichment on the Open-Field Behavior of Wild and Domestic Norway Rats. Journal of Comparative and Physiological Psychology, 89, 892-898. http://dx.doi.org/10.1037/h0077160

Hughes, C. W. (1975). Early Experience in Domestication. Journal of Comparative and Physiological Psychology, 88, 407417. http://dx.doi.org/10.1037/h0076214

Hughes, C. W., \& Boice, R. (1973). Domestication, Sophistication, and Avoidance in Norway Rats. Journal of Comparative and Physiological Psychology, 84, 408-413. http://dx.doi.org/10.1037/h0035285

Jones, M. A., Mason, G., \& Pillay, N. (2011). Early Environmental Enrichment Protects Captive-Born Striped Mice against the Later Development of Stereotypic Behaviour. Applied Animal Behaviour Science, 135, 138-145.

http://dx.doi.org/10.1016/j.applanim.2011.08.015

Komorowska, J., \& Pisula, W. (2003). Does Changing Levels of Stress Affect the Characteristics of Grooming Behavior in Rats? International Journal of Comparative Psychology, 16, 237-246.

Krech, D., Rosenzweig, M. R., \& Bennett, E. L. (1962). Relations between Brain Chemistry and Problem-Solving among Rats Raised in Enriched and Impoverished Environments. Journal of Comparative and Physiological Psychology, 55, 801-807. http://dx.doi.org/10.1037/h0044220

Latham, N., \& Mason, G. (2010). Frustration and Perseveration in Stereotypic Captive Animals: Is a Taste of Enrichment Worse Than None at All? Behavioural Brain Research, 211, 96-104. http://dx.doi.org/10.1016/j.bbr.2010.03.018

Leggio, M. G., Mandolesi, L., Federico, F., Spirito, F., Ricci, B., Gelfo, F., \& Petrosini, L. (2005). Environmental Enrichment Promotes Improved Spatial Abilities and Enhanced Dendritic Growth in the Rat. Behavioural Brain Research, 163, 78-90. http://dx.doi.org/10.1016/j.bbr.2005.04.009

Lewis, M. (2004). Environmental Complexity and Central Nervous System Development and Function. Mental Retardation and Developmental Disabilities Research Reviews, 10, 91-95. http://dx.doi.org/10.1002/mrdd.20017

Lickliter, R., \& Ness, J. (1990). Domestication and Comparative Psychology: Status and Strategy. Journal of Comparative Psychology, 104, 211-218. http://dx.doi.org/10.1037/0735-7036.104.3.211

Lockard, R. B., \& Haerer, H. (1968). Time Course of Change in Light Preference Resulting from Prolonged Exposure to Adapting Stimuli. Journal of Comparative and Physiological Psychology, 65, 529-531. http://dx.doi.org/10.1037/h0025825

Mailloux, J. G., Edwards, H. P., Barry, W. F., Rowsell, H. C., \& Achorn, E. G. (1974). Effects of Differential Rearing on Cortical Evoked Potentials of the Albino Rat. Journal of Comparative and Physiological Psychology, 87, 475-480. http://dx.doi.org/10.1037/h0036956

Manosevitz, M., \& Joel, U. (1973). Behavioral Effects of Environmental Enrichment in Randomly Bred Mice. Journal of Comparative and Physiological Psychology, 85, 373-382. http://dx.doi.org/10.1037/h0035041

McCall, R. B., Lester, M. L., \& Dolan, C. G. (1969). Differential Rearing and the Exploration of Stimuli in the Open Field. Developmental Psychology, 1, 750-762. http://dx.doi.org/10.1037/h0028200

Mitchell, D. (1976). Experiments on Neophobia in Wild and Laboratory Rats: A Reevaluation. Journal of Comparative and Physiological Psychology, 90, 190-197. http://dx.doi.org/10.1037/h0077196

Moncek, F., Duncko, R., Johansson, B. B., \& Jezova, D. (2004). Effect of Environmental Enrichment on Stress Related Systems in Rats. Journal of Neuroendocrinology, 16, 423-431. http://dx.doi.org/10.1111/j.1365-2826.2004.01173.x

Morley-Fletcher, S., Rea, M., Maccari, S., \& Laviola, G. (2003). Environmental Enrichment during Adolescence Reverses the Effects of Prenatal Stress on Play Behaviour and HPA Axis Reactivity in Rats. European Journal of Neuroscience, 18, 3367-3374. http://dx.doi.org/10.1111/j.1460-9568.2003.03070.x

Ottoni, E. B. (2000). EthoLog 2.2: A Tool for the Transcription and Timing of Behavior Observation Sessions. Behavior 
Research Methods, Instruments, \& Computers, 32, 446-449. http://dx.doi.org/10.3758/BF03200814

Pisula, W. (2003). The Roman High- and Low-Avoidance Rats Respond Differently to Novelty in a Familiarized Environment. Behavioural Processes, 63, 63-72. http://dx.doi.org/10.1016/S0376-6357(03)00032-9

Pisula, W. (2004). Response to Novelty in Low-Stress Conditions in Rats. Polish Psychological Bulletin, 35, 99-103. http://cejsh.icm.edu.pl/cejsh/element/bwmeta1.element.77701953-5e92-30e6-80bb-834ad95d6230

Pisula, W. (2007). Stimulus and Information Seeking Behavior-A Comparative and Evolutionary Perspective. In L. V. Brown (Ed.), Psychology of Motivation (pp. 167-179). New York: Nova Science Publishers, Inc.

Pisula, W., Ostaszewski, P., \& Matysiak, J. (1992). Effects of Physical Environment and Social Experiences on Stimulus Seeking Behavior and Emotionality in Rats (Rattus norvegicus). International Journal of Comparative Psychology, 5, 124-137.

Pisula, W., Turlejski, K., Stryjek, R., Nałęcz-Tolak, A., Grabiec, M., \& Djavadian, R. L. (2012). Response to Novelty in the Laboratory Wistar rat, Wild-Captive WWCPS Rat, and the Gray Short-Tailed Opossum (Monodelphis domestica). Behavioural Processes, 91, 145-151. http://dx.doi.org/10.1016/j.beproc.2012.06.010

Price, E. O. (1999). Behavioral Development in Animals Undergoing Domestication. Applied Animal Behaviour Science, 65, 245-271. http://dx.doi.org/10.1016/S0168-1591(99)00087-8

Reinhardt, V. (2003). Compassion for Animals in the Laboratory: Impairment or Refinement of Research Methodology? Journal of Applied Animal Welfare Science, 6, 123-130. http://dx.doi.org/10.1207/S15327604JAWS0602_04

Sackett, G., Novak, M., \& Kroeker, R. (1999). Early Experience Effects on Adaptive Behavior: Theory Revisited. Mental Retardation and Developmental Disabilities Research Reviews, 5, 30-40. http://dx.doi.org/10.1002/(SICI)1098-2779(1999)5:1<30::AID-MRDD4>3.0.CO;2-J

Stryjek, R. (2008). Devices for Handling Small Mammals in Laboratory Conditions. Acta Neurobiologiae Experimentalis, 68, 407-413.

Stryjek, R., \& Modlinska, K. (2013). A Thigmotaxis-Based Method of Recapturing and Transporting Small Mammals in the Laboratory. Lab Animal, 42, 321-324. http://dx.doi.org/10.1038/laban.328

Stryjek, R., \& Pisula, W. (2008). Warsaw Wild Captive Pisula Stryjek Rats (WWCPS)—Establishing a Breeding Colony of Norway Rat in Captivity. Polish Psychological Bulletin, 39, 67-70. http://dx.doi.org/10.2478/v10059-008-0011-x

Stryjek, R., Modlińska, K., \& Pisula, W. (2012). Species Specific Behavioural Patterns (Digging and Swimming) and Reaction to Novel Objects in Wild Type, Wistar, Sprague-Dawley and Brown Norway Rats. PLOS ONE, 7, e40642. http://dx.doi.org/10.1371/journal.pone.0040642

Swaisgood, R. R., White, A. M., Zhou, X., Zhang, G., \& Lindburg, D. G. (2005). How Do Giant Pandas (Ailuropoda melanoleuca) Respond to Varying Properties of Enrichments? A Comparison of Behavioral Profiles among Five Enrichment Items. Journal of Comparative Psychology, 119, 325-334. http://dx.doi.org/10.1037/0735-7036.119.3.325

Tanaś, L., \& Pisula, W. (2011). Response to Novel Object in Wistar and Wild-Type (WWCPS) Rats. Behavioural Processes, 86, 279-283. http://dx.doi.org/10.1016/j.beproc.2010.12.018

Tanaś, L., \& Stryjek, R. (2008). Response to Novelty in Rats Tested in Isolation and in Pairs: Focus on Exploration and Play. Polish Psychological Bulletin, 39, 81-88. http://dx.doi.org/10.2478/v10059-008-0012-9

Thor, D., Harrison, R., Schneider, R., \& Carr, W. (1988). Sex Differences in Investigatory and Grooming Behaviors of Laboratory Rats ( Rattus norvegicus) Following Exposure to Novelty. Journal of Comparative Psychology, 102, $188-192$. http://dx.doi.org/10.1037/0735-7036.102.2.188 
Scientific Research Publishing (SCIRP) is one of the largest Open Access journal publishers. It is currently publishing more than 200 open access, online, peer-reviewed journals covering a wide range of academic disciplines. SCIRP serves the worldwide academic communities and contributes to the progress and application of science with its publication.

Other selected journals from SCIRP are listed as below. Submit your manuscript to us via either submit@scirp.org or Online Submission Portal.
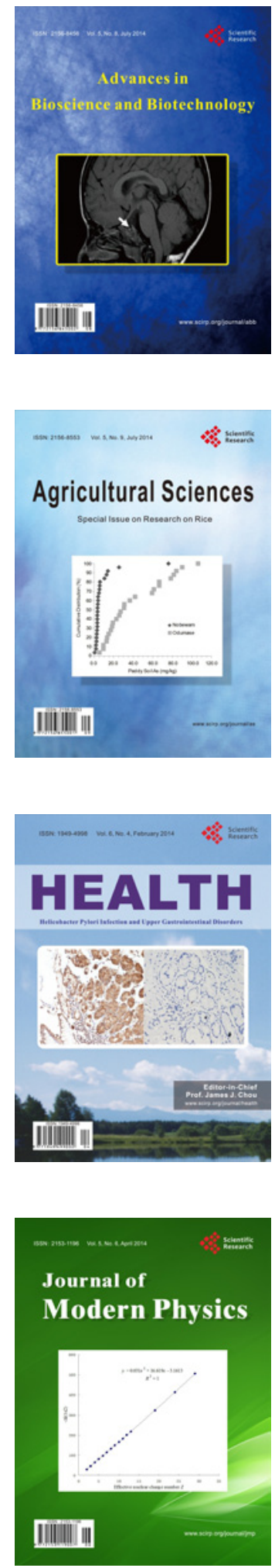


Creative Education
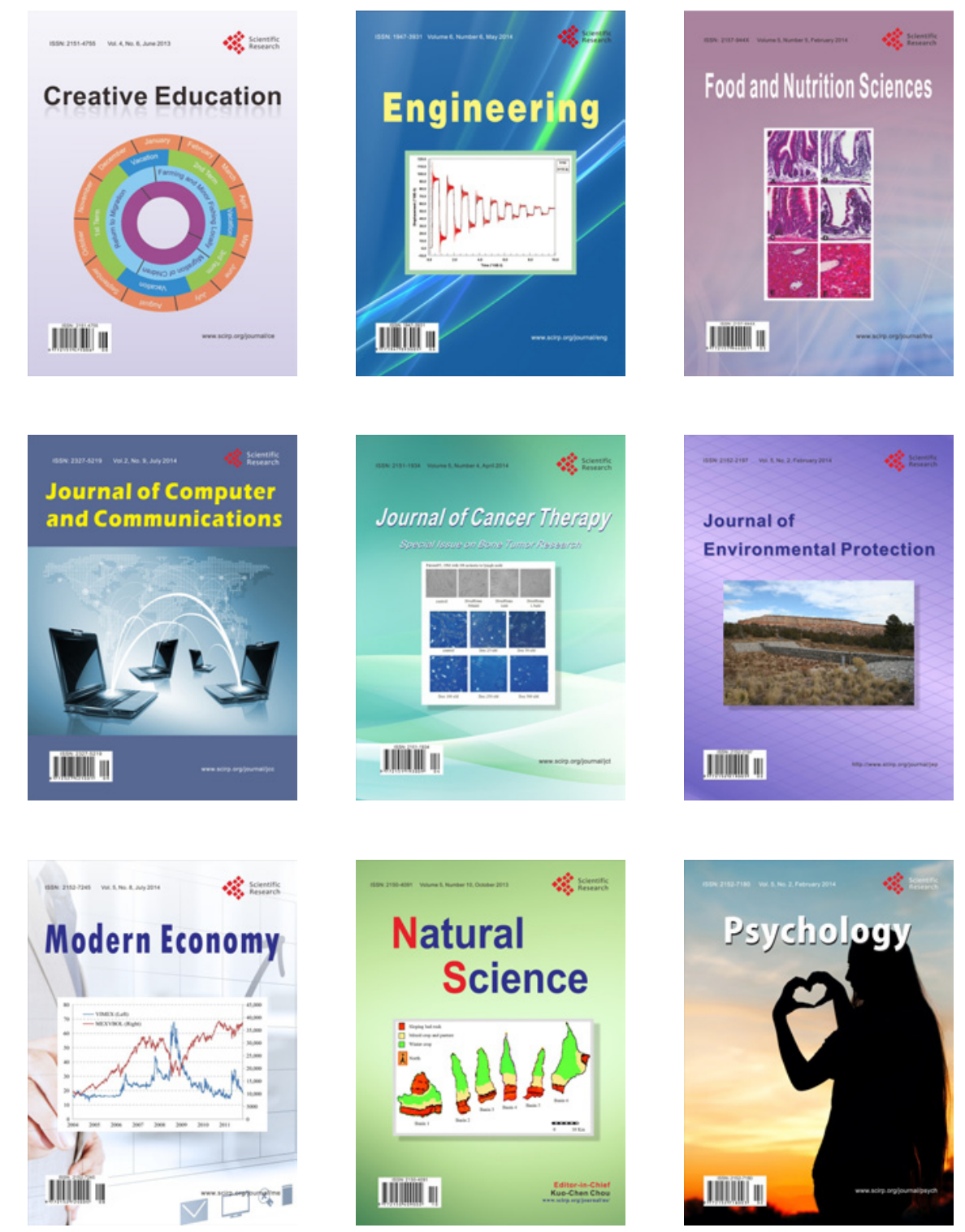